\title{
Complexidade narrativa na série Homens?: estudo baseado em técnicas de decupagem e categorização
}

\section{Narrative complexity in the Homens?: study based on breaking down the script and categorization techniques}

\author{
Ligia Prezia Lemos ${ }^{1}$
}




\section{Resumo}

Este artigo realiza uma exploração metodológica de técnicas de análise de ficção televisiva com características complexas. Investiga elementos de complexidade narrativa (MITTELL, 2012) na série Homens? (Comedy Central, 2019) a partir de dois eixos: seu nível discursivo, que remete ao conceito de merchandising social como recurso comunicativo (LOPES, 2009); e seu nível narrativo, por apresentar um conjunto heterogêneo de artifícios para leitura e compreensão do discurso proposto, alicerçado em técnicas de storytelling. Construímos tal classificação a partir de decupagem das cenas, acompanhando a própria estrutura narrativa desses eixos que se entrecruzam dialogicamente para amplificar a discussão sobre as temáticas propostas.

Palavras-chave

Ficção televisiva brasileira, série brasileira, metodologia, recurso comunicativo, narrativa complexa.

\section{Abstract}

This article performs a methodological exploration of television fiction analysis techniques with complex characteristics. It investigates elements of narrative complexity (MITTELL, 2012) that are present in the series Homens? (Comedy Central, 2019) from two axis: its discursive level, which refers to the concept of social merchandising as a communicative resource (LOPES, 2009); and its narrative level, as it presents a heterogeneous set of devices for reading and understanding the proposed discourse, based on storytelling techniques. We built such a classification from the breaking down of the scenes, following the narrative structure of these axes that dialogically intertwine to amplify the discussion on the proposed themes.

\section{Keywords}

Brazilian television fiction, Brazilian series, methodology, communicative resource, complex narrative. 
Frente à investida conservadora e sexista emergente no atual cenário brasileiro é, no mínimo, uma experiência interessante assistir à série Homens? (COMEDY CENTRAL, 2019-atual)² com suas características de deslocamento em relação às abordagens presentes no gênero comédia no Brasil. De uma perspectiva cômica, enfrenta assuntos intrincados relacionados à masculinidade, e traz aspectos de inovação no que diz respeito à complexidade narrativa e à utilização de efeitos especiais narrativos (MITTELL, 2012).

Mais do que ousadia estética, a série assume para si a função de exposição ativa de questões relacionadas ao que podemos nomear de merchandising social, e que também se aproxima de uma espécie de ativismo por parte do autor, conforme se observa em reportagens e material de divulgação. Fique claro, de início, que é uma comédia ousada e até obscena, aos moldes de muitas que marcam a produção brasileira, mas que, no caso, investe em um profundo debate sobre o mundo masculino por meio de questões internas da diegese e, consequentemente, da vida interior dos personagens. Assim, o questionamento e as transformações pessoais referentes a conceitos arraigados nos personagens, quanto a atitudes e pensamentos, refletem na cultura ficcional em que estão inseridos, uma mimesis da nossa, brasileira.

Podemos assumir, também, que a série apresenta traços do realismo grotesco, em que a imagem grotesca se caracteriza por fenômenos que estão em processo de transformação, mas que ainda não se completaram (BAKHTIN, 2010, p. 21) tanto na obra quanto na própria realidade brasileira. Aborda transformações pessoais dos personagens, que transcorrem paralelas e inacabadas, sendo que as rupturas narrativas propostas podem se revelar difíceis para a audiência, que reverbera seu desgosto na internet onde a discussão passa pelos espectadores mais conservadores, que protestam quanto à abordagem aberta e "indecorosa" de

Escrita por Fábio Porchat, a série é um projeto do Comedy Central coproduzido pelo VIS, Viacom International Studios, e Porta dos Fundos, em parceria com a Amazon Prime Video. A primeira temporada estreou em 18 de março de 2019 e, a segunda, em 14 de abril de 2020, no canal pago Comedy Central no Brasil. Após cada exibição, os capítulos inéditos eram disponibilizados na plataforma on-line do canal (comedycentral.com.br) e no VoD da Amazon (primevideo.com). Com direção de Johnny Araújo, o elenco conta com Fábio Porchat, Rafael Portugal, Gabriel Godoy, Raphael Logam, Gabriel Louchard, Miá Mello, Cintia Rosa, Giselle Fróes, Giselle Batista, Yuri Marçal, Lua Branco. A série Homens? também oferece conteúdo transmídia, além do linear. São dois spin-off semanais, o "Canal do Pau" e o "Stand Up do Pau", com Rafael Portugal, disponíveis no canal do Comedy Central Brasil no YouTube e no aplicativo CC Play. 
aspectos da sexualidade e da linguagem utilizada; e os mais engajados, que não aceitam a exibição do machismo explícito, porém necessário para que a audiência possa acompanhar as metamorfoses que se darão a seguir na narrativa ${ }^{3}$.

\section{A série Homens?}

A série Homens? é uma série brasileira híbrida que se insere no gênero cômico, mas que trafega pelo humorístico, pela sitcom, pelo non sense e, por vezes, até, pelo drama. Apresenta para o telespectador os problemas do cotidiano dos personagens de maneira engraçada, com muitos fios narrativos entretecidos, e levanta debates por meio do humor. Até o momento estão disponíveis duas temporadas, com oito episódios de meia hora cada. Alexandre (Fabio Porchat), homem na faixa dos 30 anos, publicitário de sucesso, está passando por um transtorno de impotência sexual há mais de um ano. Já no início da série ele resolve contar seu problema para os amigos mais próximos, que o apoiam e procuram ajudá-lo. São três amigos muito íntimos: o médico Pedro (Gabriel Louchard); o empresário Pedrinho (Raphael Logam); e o desempregado Gustavo (Gabriel Godoy), imaturo e ainda sem profissão definida. Há, ainda, um elemento inusitado: trata-se do pênis do personagem Alexandre, antropomorfizado como o personagem Pau, que é representado pelo ator Rafael Portugal caracterizado de maneira caricata e desprovida de requinte ou sofisticação estética.

Ambientada na cidade do Rio de Janeiro, a série aborda questões intrinsecamente relacionadas à masculinidade tóxica e ao machismo estrutural, temas que se desenrolam de maneira que as posições machistas assumidas vão aos poucos dando lugar a questionamentos e mudanças de atitude dos personagens. Em meio a debates inseridos na trama sobre o politicamente 
correto, críticas à sociedade e à própria identidade brasileira, há também abertura de espaço para assuntos tabus como aborto, sexo anal, pansexualidade, sexo grupal, swing, liberdade sexual. Tais temas são discutidos, problematizados e ocasionalmente se integram à diegese, sendo dramatizados e aprofundados. Por fim, há a presença constante de conteúdos relativos à diversidade e inclusão, que perpassam os episódios por meio da participação naturalizada de atores e/ou personagens cadeirantes, negros, obesos, sem que tais condições sejam debatidas ou questionadas em excesso.

Desenvolvemos para o presente trabalho uma metodologia de análise da série a partir de dois planos: o discursivo, condutor da diegese, da realidade da trama; e o narrativo, que diz respeito a elementos oníricos, inflexões críticas, criativas, com mundos e realidades paralelas. A história transita por esses planos de maneira harmônica e constante, desde o primeiro episódio, levando a audiência a compreender tal mecanismo já a partir dos primeiros momentos da primeira temporada.

\section{De rupturas e complexidades}

A ficção televisiva ${ }^{4}$ brasileira articula características de modernidade com processos culturais anteriores e, assim, vai se alterando segundo as lutas do espaço social em que está inserida. Reflete, assim, os processos intrínsecos da própria TV, que atualmente passa por alterações estruturais em suas lógicas de produção e de recepção (MARTÍN-BARBERO, 2009). A programação, por exemplo, primeiramente passou dos sistemas de distribuição para os de fluxo e, agora, para a complexidade da rede.

A ficção televisiva comporta, ainda, a influência do telespectador por meio de telas, plataformas, molduras que incentivam a interação; sendo que suas práticas cotidianas não dependem mais de horários e grades, o que traz consequências inclusive para os resultados das medições de audiência. Questão relevante ao se levar em conta que os sistemas de radiodifusão anteriormente 
baseavam a programação televisiva na "análise da distribuição de interesses ou categorias num programa" (WILLIAMS, 2016, p. 96). Ora, os bens culturais podem ser aprimorados, pois são materiais, ou seja, são resultado dos meios de produção, e justamente por essa razão, formações sociais e formas culturais são imbricadas, se rearranjando continuamente.

Hoje presenciamos novas formas culturais em desenvolvimento, mas que conservam aquele sentido proposto por Williams (2016), ou seja, relacionando cultura com os modos de produção. Cultura representa força produtiva com consciência prática, o que possibilita certos deslocamentos, especialmente em termos de temática e de linguagem nas obras de ficção televisiva no Brasil e, nessa pesquisa específica, do gênero comédia.

Na ficção televisiva, a complexidade narrativa, em um primeiro momento, refere-se à combinação entre o que é série (episódica) e o que é seriado (em capítulos $)^{5}$, no sentido da trama conter simultaneamente eixos narrativos curtos e longos (MITTELL, 2012). Os eixos narrativos, também chamados de arcos dramáticos, são uma espécie de respiração da história, o ritmo, o que dá vida e dinâmica às narrativas (VOGLER, 2006). As produções que apresentam complexidade narrativa são aquelas que abrangem dentro de um mesmo capítulo/episódio uma história que começa e termina (eixo curto) somada a uma história que vai continuar no próximo episódio (eixo longo). A complexidade narrativa amplia oportunidades criativas - além de não se mostrar tão uniforme ou rígida quanto as convenções anteriores - sendo que essas inovações nos formatos estão diretamente ligadas a forças históricas e culturais que transformam normas passadas.

Também se observa na narrativa complexa um processo de mão dupla, pois que demanda do espectador certa ginástica mental, como se fosse necessário bastante problematizadas. Em termos estritos, o arco narrativo da série é estruturado como uma situação e um conjunto fixo de personagens, com acontecimentos que se iniciam e vão sendo solucionados durante o próprio episódio, praticamente independente dos que vieram antes ou dos que virão a seguir. Seu encadeamento narrativo ocorre, portanto, em episódios. Já o arco narrativo do seriado possui uma progressão narrativa que vai acompanhando todos os capítulos, até chegar a uma conclusão no final, o que acontece, por exemplo, em minisséries e telenovelas. Seu encadeamento narrativo se dá em capítulos (ver LEMOS, 2017). 
desvendar enigmas ou resolver problemas durante sua fruição. Inseridas nesse contexto, as comédias complexas tendem a criar quebra-cabeças, a desconsiderar a verossimilhança e a apresentar cenas inusitadas que podem parecer inconsistentes ou excessivamente sofisticadas:

Os espectadores dessas comédias complexas como Seinfield e Arrested Development não se concentram no mundo diegético proporcionado pelas sitcoms, mas descobrem nos mecanismos criativos e na habilidade dos produtores em garantir essas estruturas complexas uma maneira de acompanhar o que Sconce denomina metarreflexiva (MITTELL, 2012, p. 42).

As comédias complexas exibem uma qualidade de estética operaciona/6, ou seja, é como se despertassem no telespectador, além do fruir da história, um desejo de compreender o que o autor (autores, diretores) vai elaborar criativamente para resolver determinada situação cômica: há uma curiosidade de descobrir qual procedimento narrativo será acionado. Nesses casos, a obra estimula uma autoconsciência, que vai além da reflexividade - por isso metarreflexiva - e gera no telespectador um desejo de "ver as engrenagens funcionando, nos maravilhando com a artimanha necessária para realizar tais pirotecnias narrativas" (MITTELL, 2012, p. 42).

Outra qualidade significativa da narrativa complexa em termos estéticos é sua capacidade de proporcionar no telespectador a sensação de estar presenciando uma espécie de efeito especial, que seria, na realidade, um efeito especial narrativo. Tal efeito se dá dentro da própria forma narrativa, e faz o telespectador parar de acompanhar a história em si para se deter na técnica que foi utilizada - e que Ihe causou tanto arrebatamento. As mudanças no espaço midiático da atualidade incentivam desdobramentos estéticos e possibilitam experimentações da comédia de ficção televisiva, tanto profissionais (Porta dos Fundos, Globoplay7) quanto amadoras (webséries caseiras, vídeos no YouTube). 
De acordo com Bakhtin, os processos de transformação possuem uma estética em que podemos vislumbrar traços do realismo grotesco, em que a imagem grotesca se caracteriza por fenômenos que estão se transfigurando, mas que ainda não completaram o processo (2010, p. 21). Assim, possuem fronteiras estéticas mal definidas e, devido a essa característica, possibilidades de leitura mais abertas. O realismo grotesco e o sistema de imagens da cultura cômica popular transitam pela via da predominância de demonstrações da vida corporal e da vida material, exibidas de maneira marcada e exagerada. Emprestamos esse conceito de Bakhtin (2010) quando trata do período do Renascimento, com heranças da Idade Média, na Europa do século XVI. Assim, no realismo grotesco, as festividades ligadas à matéria e ao corpo indicam que "o cósmico, o social e o corporal estão ligados indissoluvelmente numa totalidade viva e indivisível. É um conjunto alegre e benfazejo" (BAKHTIN, 2010, p. 17). Nesse sistema de imagens, questões referentes à matéria e ao corpo são vistas como questões universais que carregam em si fertilidade, crescimento, abundância, alegria, festividade.

Emerge aqui, também, uma ideia de rebaixamento, que principia nas representações abstratas, espirituais e elevadas e termina no plano da matéria e do corpo, com suas expressões relacionadas à bebida, comida, digestão e vida sexual. O realismo grotesco se afasta da nobreza presente na literatura e na arte (relacionadas a tudo o que está no alto, na cabeça, no rosto) e se degrada em direção à matéria, à terra (o baixo, a genitália, a barriga, o traseiro). Mas o baixo é produtivo, é a vida, é o começo:

Degradar significa entrar em comunhão com a vida da parte inferior do corpo, a do ventre e dos órgãos genitais, e portanto com atos como o coito, a concepção, a gravidez, o parto, a absorção de alimentos e a satisfação das necessidades naturais. A degradação cava o túmulo corporal para dar lugar a um novo nascimento. $E$ por isso não tem somente um valor destrutivo, negativo, mas também um positivo, regenerador: é ambivalente, ao mesmo tempo negação e afirmação (BAKHTIN, 2010, p. 19).

Tal concepção, presente na Idade Média, perde um pouco sua força no Renascimento e se altera substancialmente na contemporaneidade, que restringe 
seu naturalismo e caráter festivo a um erotismo trivial. Nesse sentido, o realismo grotesco pode até parecer inadequado a reflexões contemporâneas, imbricadas em grande parte com o belo, o visualmente agradável, o suavizado por filtros.

Entretanto, a vitalidade presente na imagem grotesca, nos fenômenos em processo de transformação, nas metamorfoses ainda incompletas (BAKHTIN, 2010, p. 21) está relacionada ao tempo e à evolução. São imagens ambivalentes, associadas a ciclos de início e fim, vida e morte, velho e novo. Trazem em si a beleza e o horror da materialidade, nunca concretizada, mas em eterno processo de um corpo cheio de orifícios em atos de copular, comer, beber, engravidar, parir, desagregar, envelhecer. O exato contrário das imagens clássicas do corpo perfeito. Muitas das grosserias da linguagem moderna também derivam dessa concepção do corpo, e endereçam para o baixo corporal, porém com alguma perda daquele caráter ambivalente e regenerador.

\section{Merchandising social}

No Brasil, considera-se merchandising social a ação de caráter pedagógico ou educativo, que apresente temas sociais no interior da trama de ficção televisiva. O merchandising social prioriza estratégias discursivas que, além de colocar determinado tema ou temática em pauta, é capaz de gerar um ambiente favorável para sua discussão. Considerado como característica genuína da telenovela brasileira, o merchandising social é recurso comunicativo "capaz de falar com as audiências e sobre as audiências; apontar anseios, levantar questões polêmicas e abrir espaço na trama ficcional para discussões de caráter social" (LEMOS et al., 2012). Tais discussões ampliam o interesse do telespectador e ultrapassam o desenrolar da narrativa, sendo capazes de construir um diálogo entre ficção e realidade, por meio da abordagem de pautas temática e socialmente relevantes. 
O merchandising social pode ser definido como um recurso comunicativo que consiste na veiculação em tramas e nos enredos das produções de teledramaturgia de mensagens socioeducativas explícitas, de conteúdo ficcional ou real (LOPES, 2009, p. 38).

Estamos diante, portanto, de um compromisso ideológico do autor (ou da produtora, emissora, distribuidora) com ações que levam os personagens - mesmo que estejam envolvidos com seus dramas pessoais na diegese - a assumirem "o papel de formadores de opinião, porta-vozes de inovações socioculturais" (NICOLOSI, 2009), abrindo um diálogo com questões da atualidade do mundo em que vivem. O merchandising social tem a função de trazer para a discussão temas que estariam ainda abaixo da superfície do tecido social, questões ainda pouco discutidas, mas que já possuem algum espaço de circulação, sendo que, ainda, "geram uma extensa paratextualidade que ultrapassa em muito os chamados meios de comunicação de massa e estabelecem um diálogo incessante com a sociedade" (MUNGIOLI et al., 2011).

Para analisar esta série de ficção televisiva com características complexas, nossa pesquisa se ancorou na exploração e experimentação metodológica de técnicas de análise de conteúdo (BARDIN, 2002), em que procuramos empreender uma préanálise, por meio de decupagem ${ }^{9}$, seguida da categorização das cenas. Para isso:

I. realizamos o registro de situações dramáticas, temáticas e recursos narrativos das cenas da série Homens?; e, posteriormente,

II. trabalhamos com o tratamento desses dados, sua categorização e análise.

Com apoio na própria estrutura que foi sendo apreendida no decorrer do levantamento, o trabalho de reflexão metodológica nos conduziu à observação de que estávamos diante de dois grandes aspectos - ou eixos: realizamos o processo inverso, pois decupamos o produto, com o objetivo de realizar o levantamento de dados para o presente estudo. Esta técnica também é utilizada em alguns documentários, quando o material bruto já foi filmado, mas necessita de uma decupagem para que possa ser analisado e roteirizado a posteriori. Ver: AIC. O que é uma decupagem? Disponível em: https://www.aicinema.com.br/o-que-e-uma-decupagem/. Acesso em: jul. 2020. 
1. Eixo 1: Refere-se às temáticas abordadas, e endereça ao nível discursivo, em que há a presença de determinadas questões socialmente relevantes, que atuam como recursos comunicativos.

Nesse ponto optamos por realizar uma análise majoritariamente quantitativa. Nesse eixo, após a decupagem, foi realizado tratamento dos dados, com aplicação dos seguintes critérios: eliminar descrições mais extensas das cenas (que estavam presentes apenas para orientação durante a análise global da pesquisa) e organizar a relação dos termos referentes às temáticas abordadas, com o objetivo de criar uma nuvem de palavras ou de $\operatorname{tags}^{10}$. O sistema de nuvem de palavras permite a categorização visual para operacionalização de técnicas quantitativas, com possibilidade de classificação hierárquica:

\begin{abstract}
A nuvem de tags oferece um modelo de classificação eficiente por ser um método em que indexação pode ser definida como um conjunto de procedimentos com objetivo de expressar ou representar o conteúdo temático de documentos e suas linguagens com o intuito de uma recuperação posterior (LEMOS, 2016, p. 10).
\end{abstract}

A construção da nuvem referente às temáticas socialmente relevantes, associadas ao conceito de merchandising social, e presentes nas duas temporadas da série, também obedeceu a alguns critérios: (i) Não considerar temáticas que apareceram apenas uma vez; (ii) Agrupar temáticas semelhantes, por exemplo: impotência (para termos como brochar, impotência psicológica, impotência sexual); envelhecimento (idade, diferença de idade, novinha); drogas (bala, LSD, maconha); mulher (mulher objeto, mulher machista, poder feminino); mãe (sair da casa da mãe, morar com a mãe); sexo (sexo anal, sexo casual, sexo com chefe, sexo com desconhecidos, sexo com transexual, sexo no trabalho, sexo sem camisinha, sexo virtual).

2. Eixo 2: Diz respeito ao nível narrativo, aquele que comenta, dialoga ou ilustra determinadas questões abordadas no nível discursivo, e em 
que irrompem recursos narrativos, cômicos, alegóricos, estratégias de storytelling, alterações lógicas e cronológicas, efeitos narrativos. Neste eixo optamos por uma análise qualitativa.

Neste eixo, após a decupagem, agrupamos em categorias os recursos narrativos, cômicos, estratégias de storytelling, e realizamos análise a partir desses grupos. Os principais foram: antropomorfismo; quebra da narrativa; quebra da quarta parede; sequências fantasiosas ou oníricas; cenas para enganar ou confundir; soluções gráficas; cenas que referenciam a TV. Consideramos os fatores de suas estruturas figuradas, notadamente relativas à concepção de complexidade narrativa e efeitos especiais narrativos (MITTELL, 2012).

A estrutura metodológica construída descreve os achados em duas colunas, referentes aos dois eixos (1) e (2), sendo que: (a) Se as cenas de cada eixo estavam integradas temporal e tematicamente, o conteúdo de ambos os eixos foi colocado na mesma linha e, assim, ocupa as duas colunas; (b) Se a abordagem foi autônoma (discursiva ou narrativa), independente da cena anterior ou posterior, ou ainda com estética ou linguagem desconectada da cena em questão, o conteúdo foi colocado na linha, em apenas uma coluna (Figura 1).

(1)

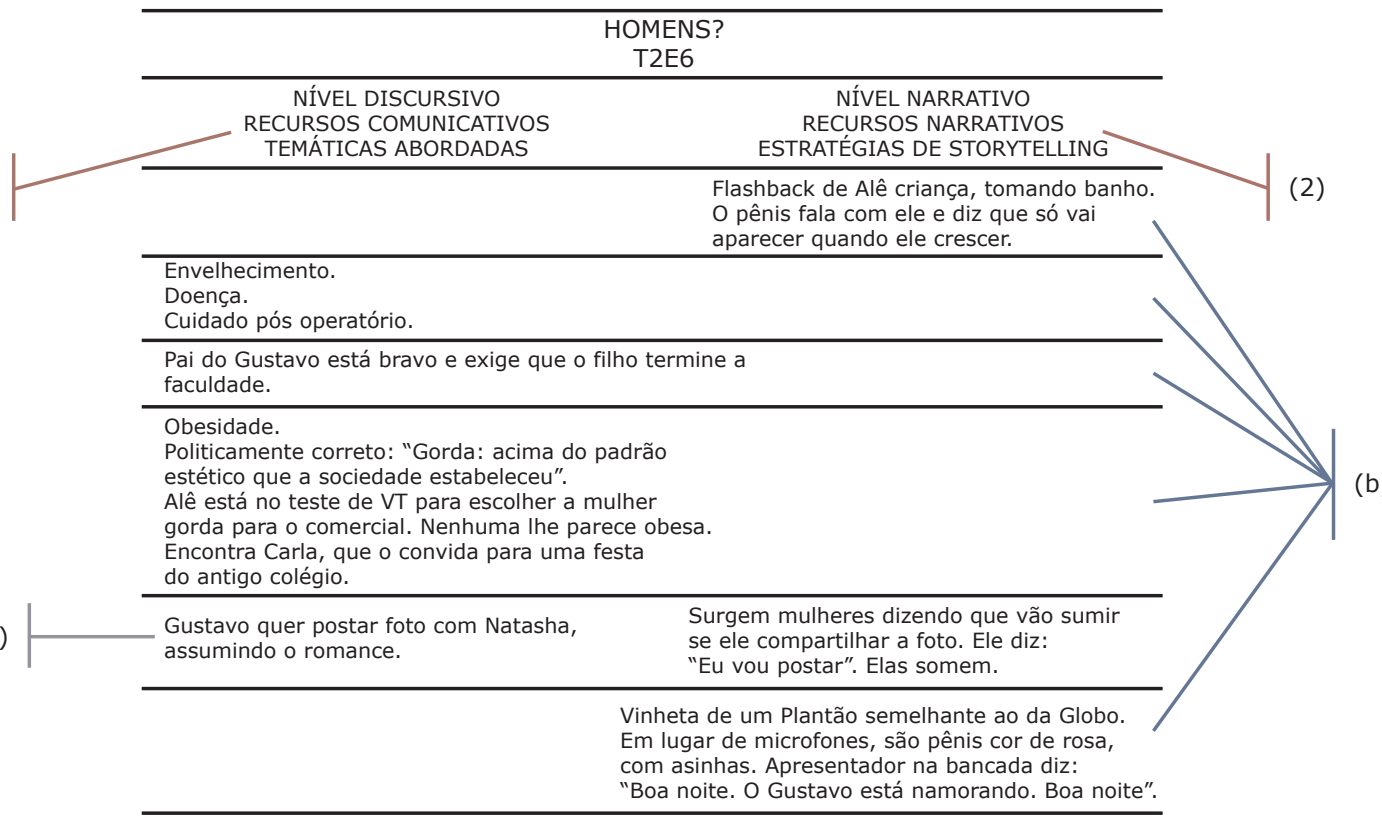

Figura 1. Estrutura metodológica, detalhe da decupagem. 
Entendemos que o rigor metodológico e o uso de técnicas adequadas propiciam uma análise aprofundada tanto dos pontos formais que estruturam a ficção televisiva, quanto de seu conteúdo propriamente dito.

\section{Nível discursivo, recursos comunicativos, temáticas abordadas (Eixo 1)}

Mais do que uma obra que ostenta em termos de ousadia estética, a série Homens? em seu nível discursivo assume para si a função de exercício do merchandising social com exposição ativa do machismo estrutural, presente e dominante na sociedade brasileira, e da masculinidade tóxica, com suas formas de ação dominantes. A série procura discutir o que significa ser homem heterossexual na contemporaneidade, seus desejos, suas inquietações, seu relacionamento com a mulher - e seu olhar para ela - enfim, como é o mundo em que o homem está inserido. Para Porchat, autor e ator,

não é para ser uma série bonitinha, e sim real. Vamos falar do que acontece de verdade no mundo do homem, abordando o machismo por e para os homens. Inclusive nas cenas de sexo, a ideia é dar o tom mais realista o possível. (...) Ao mesmo tempo em que as mulheres estão mudando, os homens precisam acompanhar esse processo. Por isso a inadequação do homem nesse meio do caminho de desconstrução machista é um dos nossos principais temas. Queremos rir disso e mostrar como os homens estão apanhando para mudar ${ }^{11}$.

Sem ser didática, a série possui uma estrutura interna em que a desconstrução do pensamento machista - imposto aos homens desde a infância e persistentemente reforçado pela família, amigos e sociedade - é gradual e passa por diferentes fases como: negação, observação, compreensão, tentativa de mudança e, finalmente, a busca de aplicação do aprendizado. Parte da construção do personagem principal da série se ancora no fato de que, mesmo com a nova consciência, ele encontra dificuldades e lutas internas, nas quais os pensamentos machistas se mostram 
resistentes; e lutas externas, com as pessoas de sua convivência que persistem com velhos pensamentos e hábitos.

Dentro deste contexto da masculinidade a série discute, com maior ou menor intensidade, questões sociais adjacentes - por vezes polêmicas, e por vezes assuntos que são tabus - como o lugar da mulher na sociedade, impotência, sexo, prostituição, envelhecimento, uso de álcool e drogas, infidelidade, casamento, swing, representatividade racial e de gênero, assédio, aborto, masturbação, gravidez (Figura 2).

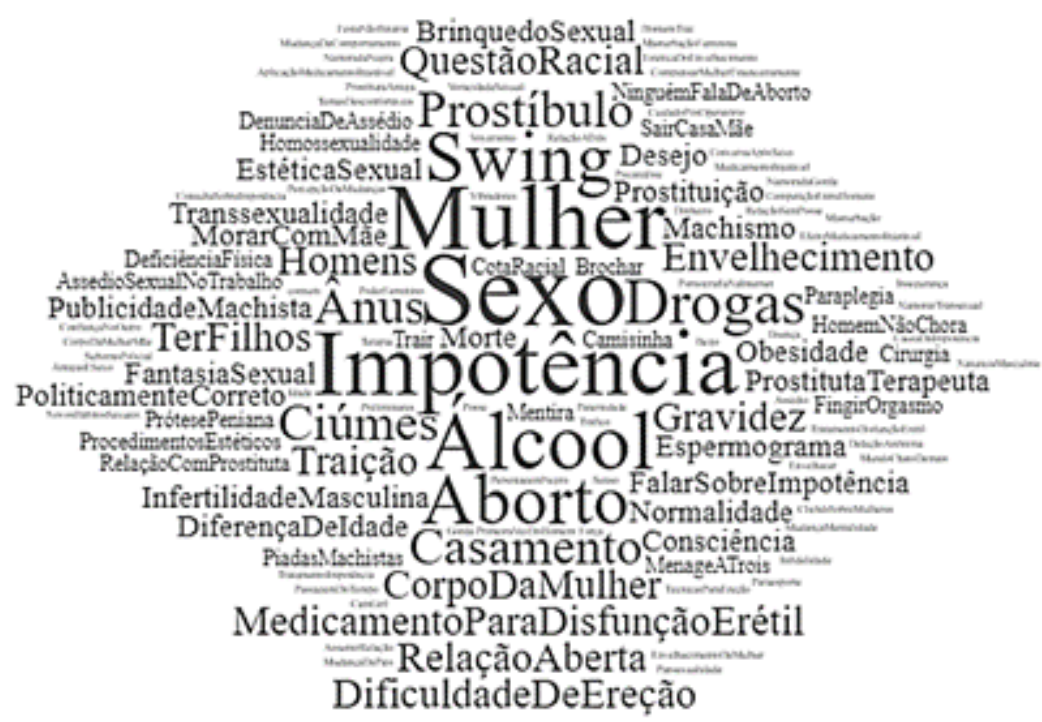

Figura 2. Nuvem de palavras - Temáticas abordadas

Fonte: pesquisa da autora.

Com o objetivo de ilustrar um exemplo da estrutura interna que funciona como recurso comunicativo na série Homens? destacamos uma cena da T1E7 ${ }^{12}$ : Alexandre está insatisfeito como redator de peças publicitárias na agência em que trabalha. Sua atuação tem Ihe revelado que está sendo um perpetuador do pensamento machista na forma como representa a mulher. Arrepende-se disso, mas mesmo assim é levado a criar uma nova campanha para determinada marca de esmalte, e que reforça o pior do senso comum. Ao manifestar seu 
descontentamento, é criticado por seu chefe que, por sua vez, está chateado com o pensamento politicamente correto de seu funcionário e da sociedade em geral. Já a personagem Raquel (Maytê Piragibe), atendimento da agência, é um exemplo de mulher machista que acredita que tudo isso é coisa de feministas que não gostam de ser mulheres e que Alexandre, por ter esse tipo de postura, é um "feminazi". Descontente com a situação, ele pede demissão e questiona: "Você já teve que fazer alguma coisa só porque você é homem?".

De acordo com acontecimentos anteriores e posteriores a tal questionamento, podemos depreender que este foi o episódio em que Alexandre começou a tomar consciência. O que fica demonstrado, a seguir, na T1E8, em que Alexandre diz no WhatsApp: "Não é porque é homem que tem que ficar falando putaria o tempo todo". E sai do grupo. Em seu eixo discursivo, a série busca levantar e aprofundar temáticas referentes à superação de intolerâncias, novos costumes, possibilidades de os homens experimentarem novas formas de estar no mundo, e com novas visões de mundo.

\section{Nível narrativo, recursos narrativos, estratégias de storytelling (Eixo 2)}

A série Homens? inserida dentro do conceito de narrativa complexa revela sua estética operacional já desde a primeira cena, com a participação do personagem Pau, criatura antropomorfizada (que aparece muito triste junto a um casal que tenta fazer sexo e não consegue). A presença do Pau, personificado por um ator que empresta a humanidade necessária ao personagem, é um efeito especial narrativo, que perpassa toda a série (Figura 3). Na T1E7, por exemplo, Alexandre fala para o Pau que o medicamento injetável para disfunção erétil que usou não teve o efeito desejado, não adiantou, pois a ereção que conseguiu não foi satisfatória. Em seguida, reflete que é preciso mudar a cabeça. Mas eles discutem, pois o Pau insiste e quer tomar mais injeções, por ter gostado da experiência.

A abordagem alegórica da insegurança masculina se amplia no episódio seguinte (T1E8), quando Dani chega sem avisar na casa de Alexandre e Pau quer 
tomar o medicamento novamente, e briga por isso. O efeito especial narrativo apresenta a característica de vir para o primeiro plano, revelando a natureza da construção narrativa. E os criadores, depois de certo tempo - e com as normas da série já estabelecidas - podem usar da liberdade de extrapolar ainda mais essa complexidade e suas variações. Ora, em Homens? (T2E3), Alexandre envia nudes para a namorada pelo celular e as imagens revelam o próprio personagem Pau fazendo pose: "A reflexividade operacional nos convida a pensar no ambiente ficcional ao mesmo tempo em que apreciamos sua construção" (MITTELL, 2012, p. 43).

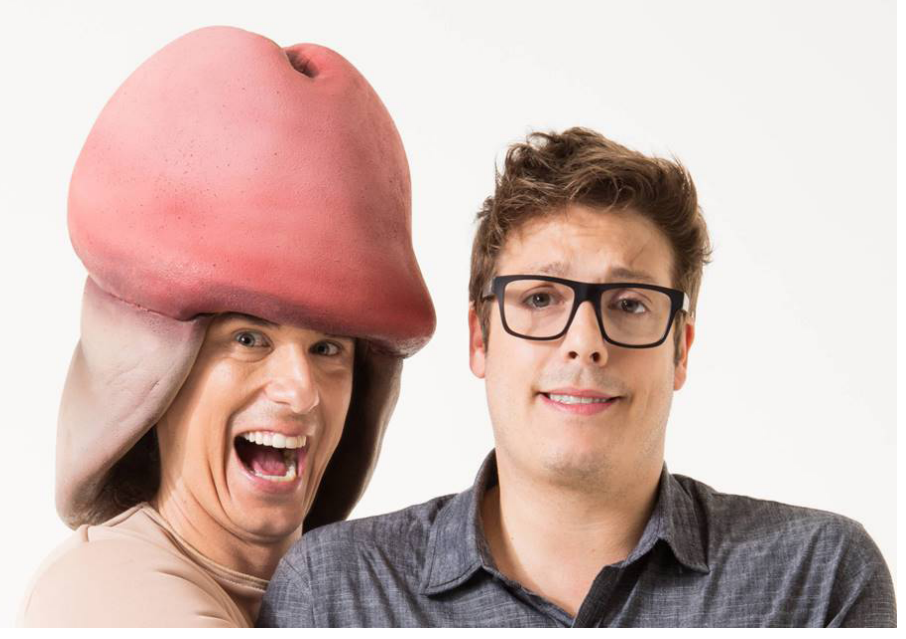

Figura 3: Pau e Alexandre.

Fonte: Comedy Central/divulgação.

A estética operacional dessa narrativa complexa se baseia em uma profusão de recursos narrativos que causam certo encanto somado a uma espécie de estranhamento. Prosseguindo com esse personagem, observamos uma mudança de perspectiva como estética operacional na T2E5 quando Alexandre conversa com seu pai, que deseja realizar uma cirurgia para colocação de prótese peniana. Nesse ponto aparece o depoimento de um personagem que é o pênis de seu pai, também antropomorfizado: ele é mais velho, e o ator usa figurino semelhante ao do Pau de Alexandre. O pênis do pai dá um depoimento para a câmera, contando sua primeira experiência sexual, que está cansado e quer descansar, por isso reclama da prótese que vai fazê-lo trabalhar ainda mais. Não bastasse, na T2E6 
há um flashback em que Alexandre, ainda criança, toma banho. O personagem Pau, agora criança, fala com ele e diz que só vai aparecer quando ele crescer.

\begin{abstract}
O público aproveita não somente as reviravoltas diegéticas, mas também as técnicas de narração excepcionais necessárias para realizar tais maquinações - regozijamo-nos tanto pela história que está sendo contada quanto pela forma com que esse contar rompe com as regras da produção televisiva (MITTELL, 2012, p. 453).
\end{abstract}

As estratégias narrativas utilizadas em Homens? podem ser impressionantes, principalmente quando tocam em pontos intimamente relacionados à psique masculina, discutida na obra. Em determinada passagem da T2E5, Raquel chega à casa de Alexandre, pois o Pau a havia chamado. E mais, como Alexandre parece problematizar demais, e está em uma crise muito grande, Pau pede que ele fique trabalhando e, moto contínuo, leva Raquel para o quarto, no colo. E chega a ser lírica a relação dos dois quando, na T2E6, eles vão se deitar para dormir, Alexandre pede um abraço para o Pau, e eles se abraçam reconciliados.

O Pau transita pelos dois eixos propostos neste trabalho, no discursivo, sendo na maior parte das vezes extremamente machista e egoísta como uma demonstração propriamente dita; e no narrativo, em efeitos especiais que extrapolam o fato de haver um ator vestindo um figurino. Na T2E1 Alexandre está na cama com Dani e coloca a camisinha; então a cena transmuta para uma praia deserta onde Pau dança feliz, quando surge uma grande camisinha sobre ele, que primeiramente estranha, mas se cobre com ela e, apesar disso, permanece feliz, dançando.

Ocorrem quebras narrativas na série Homens? tanto em relação a alterações cronológicas que não prescindem dos flashbacks e analepses, nas duas temporadas, quanto em quebras de quarta parede. Para Mittell, "a narração complexa normalmente rompe com a quarta parede" (2012, p. 45) interferindo na barreira que há entre o diegético e o não diegético. Na T2E1, Alexandre entrevista Gael (Yuri Marçal), candidato a alugar um quarto em sua casa, e combinam que isso vai acontecer "no próximo episódio". Na T2E1, Pedro compra um teste de contagem de esperma e, como está ansioso, vai 
para o banheiro de uma lanchonete próxima para colher material. Os amigos estão com ele e Alexandre comenta, surpreso, que será preciso esperar 3 minutos pelo resultado. Então, ele mesmo diz: "Ah não! O pessoal muda de canal e vai ver Discovery Home \& Health, aqueles gêmeos que decoram a casa. A produção já tem um teste pronto".

Nesse ponto entra em cena uma pessoa da produção e entrega o bastãozinho com o resultado pronto para os personagens. Temos ainda outro exemplo na T2E6 em que Pedro e Mari (Miá Mello) estão assistindo televisão. Ela quer sair, ele não quer. Mas, por fim, Pedro diz: "Vamos jantar com eles, não estou gostando dessa série não". Porém, o casal que está na série apresentada na TV comenta o comportamento de Pedro e Mari, como se eles é que fossem a ficção. Essas interrupções lógicas e cronológicas podem ser consideradas recursos de storytelling que são usados com frequência e regularidade nas narrativas complexas, obras que não temem causar confusão no telespectador (MITTELL, 2012, p. 46).

Há em Homens? uma abundância de sequências fantasiosas e oníricas, além de cenas criadas para enganar ou confundir. Muitas vezes tais cenas surgem alterando a perspectiva do telespectador para, em seguida, surpreende-lo, sem dar qualquer sinal antecipado do jogo que estavam propondo. Na T2E2, a narrativa já indicou que Natasha vai fazer um aborto e que Gustavo se ofereceu para acompanha-la. Ela está na sala de espera. Surge na tela um mundo fantasioso, onírico; e Gustavo entra na clínica como se fosse um astronauta, olhando para o ambiente através do capacete, em câmera lenta. É um lugar inóspito e desconhecido. A cena se converte em outra realidade paralela com mendigas, pobreza, e um novo ambiente, todo sujo e escuro.

A cena novamente se esvai e se transforma, finalmente, em uma clínica classe média, sintetizando as dúvidas, desconhecimento, fragilidades e medos do homem em poucos instantes. Na T2E3, Pedro e Mari estão analisando e escolhendo algo no celular. Como participam de grupos de swing, o diálogo indica que estão falando de uma mulher, e em contexto claramente machista: "Essa eu aprovo... é gringa... tem cara de novinha". Há um giro da câmera e a tela do celular revela 
que estão escolhendo uma nova cadeira de rodas para Pedro. São momentos em que a própria forma de contar a história gera desorientação.

A série dispõe, ainda, de recursos que nomeamos de soluções gráficas, com animações e formas visuais, inclusive com inserção de lettering ${ }^{13}$ para construir argumentos narrativos. O próprio logotipo carrega a indicação da proposta de transformação da masculinidade, com a palavra homens escrita em nuances de cor que vão do azul ao cor de rosa. Nesta categoria, destacamos a forma que os aplicativos são representados. Na T1E4, Pedro está com ciúmes e espiona Mari pelo "Find your device". A linguagem deste app debocha dele e a voz feminina faz inúmeros trocadilhos com a situação. Já o WhatsApp está presente em quase todos os episódios da série, na forma de simulação da tela, com os personagens interagindo em vídeo (Figura 4).

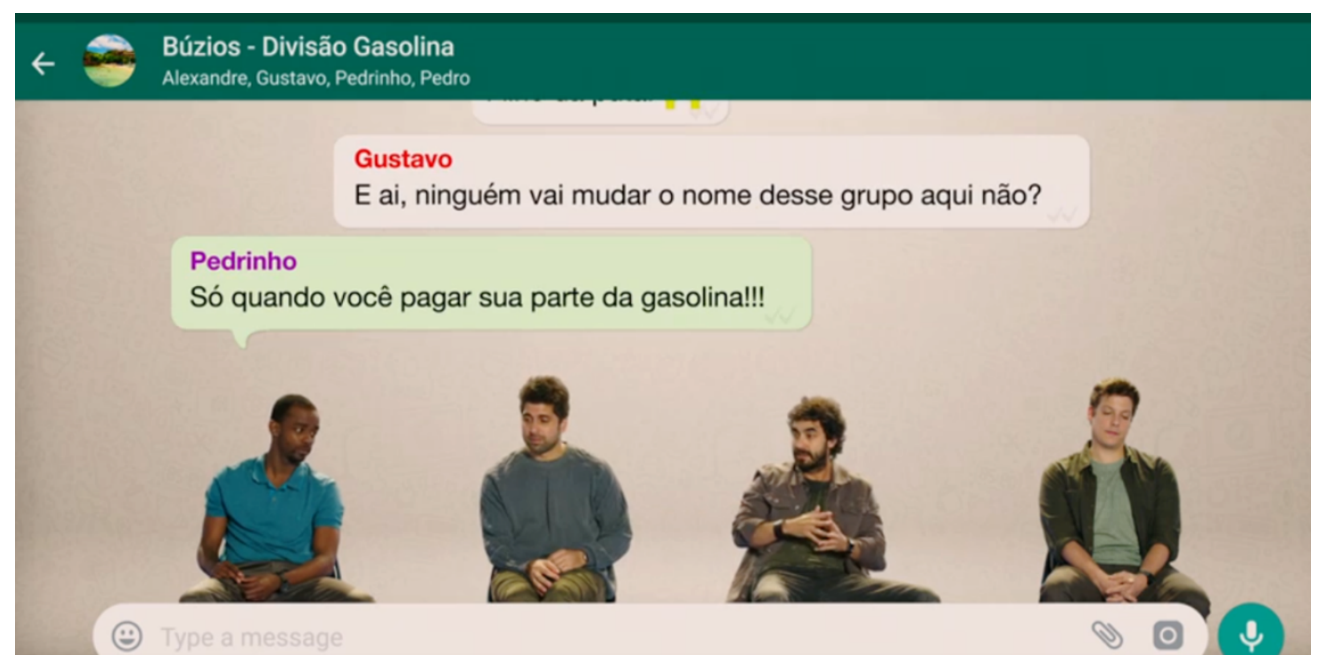

Figura 4: WhattsApp dos personagens.

Fonte: Print de cena de Homens? no Prime Video.

Por fim, há numerosas referências à TV, que podemos classificar em dois tipos: aquelas que integram artistas e apresentadores reais; e aquelas em que os próprios personagens atuam. Participaram da série Amin Kader, Sérgio Malandro, Valeska Popozuda e Cristina Rocha. Na T2E6, em meio a uma discussão entre Pedro 
e Mari, aparece esta última apresentadora dizendo: "Alô Brasil! Momento tenso no episódio de hoje" com lettering nos moldes de seu antigo programa, em que se lê: "Fiz sexo com outra mulher sem camisinha e não falei do aborto para a minha esposa". Quanto às referências do segundo tipo, os personagens participam de inúmeros quadros em formato de programas explicativos, ou críticos, ou apenas cômicos como, por exemplo, o Pau em coletiva de imprensa como se fosse um jogador de futebol (T1E2); a faxineira da casa de Pedro e Mari que quebra a quarta parede e apresenta o programa "Relacionamentos afetivos" (T1E8); o Pau que dá testemunho de conquista pessoal em programa religioso (T2E2); e uma espécie de sitcom "A vida de merda de Alexandre" (T2E7) entre outras.

Vale a pena refletir sobre o quanto a comédia complexa exige do telespectador em termos de literacia e engajamento, principalmente "no sentido de ter competências para decodificar histórias e mundos diegéticos" (MITTELL, 2012, p. 48), mundos que jogam com diferentes fronteiras, com o intuito de alcançar o efeito cômico desejado.

\section{Apontamentos finais}

Bakhtin (2010) nos indica que a paródia medieval não se parece com a paródia de nossa época, pois a paródia moderna apesar de apresentar a característica de degradação, possui um caráter negativo, sem aquela significação regeneradora original. No caso de Homens? é possível entrever trechos de qualidades produtoras e regeneradoras da terra e da corporalidade, especialmente no que se refere a uma esperança de tolerância e igualdade de gêneros. Foi concebida em momentos anteriores ao atual, em que testemunhamos a concretização de ideias conservadoras e retrógradas. Por essa razão, há uma clareza na desordem que a série retrata, em seu realismo grotesco, indicando potenciais fenômenos em processo de transformação, de metamorfose ainda incompleta (BAKHTIN, 2010, p. 21), e que infelizmente parecem ter sido interrompidos - ou adormecidos.

A série apresenta propostas esteticamente complexas para uma questão que solicita transformações ainda mais complexas na sociedade no que diz respeito à cultura machista do Brasil. Sua narrativa extrapola fronteiras estéticas rígidas, 
confundindo e esmaecendo espaços e tempos narrativos. É um exemplo do modelo narrativo que "se cruza com os campos das indústrias criativas, das inovações tecnológicas, das práticas participatórias e da compreensão dos espectadores" (MITTELL, 2012, p. 50), além de revelar um compromisso ideológico de ser portavoz de um tema relevante e urgente para a sociedade brasileira.

\section{Referências}

BAKHTIN, M. A cultura popular na Idade Média e no Renascimento: o contexto de François Rabelais. São Paulo: Hucitec, 2010.

BARDIN, L. Análise de conteúdo. Lisboa, Portugal: Edições 70, 2002.

HARRIS, N. Humbug: The Art of P. T. Barnum. Chicago: University of Chicago Press, Phoenix ed Edition, 1981.

LEMOS, L. P. Nuvem de tags como ferramenta de análise de conteúdo: uma experiência com as cenas estendidas da telenovela Passione na internet. Revista Lumina. v. 10, n. 1, abr. 2016.

. O autor-roteirista e a ficção televisiva brasileira na era transmídia. Tese (Doutorado). Escola de Comunicações e Artes, Universidade de São Paulo, 2017.

LEMOS, L. P.; KARHAWI, I.; SUZUKI, H. Um panorama da ficção televisiva em países ibero-americanos: temática e merchandising social. Comunicom. São Paulo: ESPM, 2012.

LOPES, M. I. V. Telenovela como recurso comunicativo. Revista MATRIZes, ano 3, n. 1, ago.-dez., 2009. 
MARTÍN-BARBERO, J. Dos meios às mediações: comunicação, cultura e hegemonia. Rio de Janeiro: Editora da UFRJ, 2009.

MITTELL, J. Complexidade narrativa na televisão americana contemporânea. Revista MATRIZes, v. 5, n. 2, jun. 2012.

MUNGIOLI, M. C. P.; LEMOS, L. P.; KARHAWI, I. ; BRETTAS, L. Merchandising social e ficção televisiva em países ibero-americanos: temas e produção de sentido. $1^{0}$ Congresso Mundial de Comunicação Ibero-americana. Confibercom. São Paulo: ECA-USP, 2011.

NICOLOSI, A. P. Merchandising social na telenovela brasileira: um diálogo possível entre ficção e realidade em Páginas da vida. Dissertação (Mestrado). Escola de Comunicação e Artes, Universidade de São Paulo, 2009.

VOGLER, C. A jornada do escritor: estruturas míticas para escritores. Rio de Janeiro: Nova Fronteira, 2006.

WILLIAMS, R. Televisão: tecnologia e forma cultural. São Paulo: Boitempo; Belo Horizonte: PUC Minas, 2016.

Submetido em: 1 set. 20 | aprovado em: 14 out. 20 